JHR

36,1

Received 27 October 2020 Revised 12 January 2021 Accepted 20 January 2021

\section{Influencing factors and gaps of blood donation knowledge among university and college students in Myanmar: a cross-sectional study}

\author{
Pramon Viwattanakulvanid
}

College of Public Health Sciences, Chulalongkorn University, Bangkok, Thailand, and Aye Chan Oo

Myanmar Emergency Paediatric and Neonatal Care Programme, RCPCH Global Child Health, Yangoon, Myanmar

\begin{abstract}
Purpose - Blood donation knowledge of healthy young students is crucial to donate blood voluntarily and regularly in long-term. This study aimed to determine the influencing factors on the blood donation knowledge, to identify gaps of blood donation knowledge and reasons for not donating blood among university and college students in Yangon, Myanmar.

Design/methodology/approach - Cross-section survey (May 2019) was conducted in students of Yangon Technological University (YTU) and National Management Degree College (NMDC) with the use of quota and convenience sampling method. The questionnaires covered sociodemographic characteristics, blood donation knowledge and reasons for not donating blood.

Findings - Total 320 students (129 males and 191 females) with age of 18 to 23 years old participated. Previous blood donation had statistically significant influence on blood donation knowledge scores $(\beta=0.396, p<0.001)$. Gaps of knowledge between nondonors and blood donors were recorded, especially in universal recipient blood groups, Rh blood groups, blood donation interval, eligibility criteria, transfusion-transmitted infections (TTIs), amount of blood removed in donation, benefits of blood donations and misbelief of infections from blood donation. Top three reasons for not donating blood among nondonors were (1) no opportunity, (2) fear to donate and (3) still underage to donate.

Originality/value - Blood donations programs should extend awareness-raising programs in academic society and population at large. Raising awareness should focus on the knowledge gaps such as donor eligibility, interval of blood donations, TTIs and benefits of donating blood to recipients.
\end{abstract}

Keywords Blood donation, Gap of knowledge, University students, Myanmar

Paper type Research paper

\section{Introduction}

Blood is the "river of life" that carries various important elements to and from every part of the human body. In routine, emergency medical and surgical conditions, blood transfusion is still one of the irreplaceable and major procedures that save lives [1]. Approximately 118.5

(C) Pramon Viwattanakulvanid and Aye Chan Oo. Published in Journal of Health Research. Published by Emerald Publishing Limited. This article is published under the Creative Commons Attribution (CC BY 4.0) licence. Anyone may reproduce, distribute, translate and create derivative works of this article (for both commercial and non-commercial purposes), subject to full attribution to the original publication and authors. The full terms of this licence may be seen at http://creativecommons.org/licences/by/4.0/ legalcode

Authors would like to thank you all participants in Mynmar and feel thanksful to Grants for Development of New Faculty Staff, Ratchadaphiseksomphot Endowment Fund.

Author contributions: Aye Chan Oo, MD, MPH. Literature search, data collection, analyzed data and wrote manuscript. Pramon Viwattanakulvanid, BSc. Pharm, PhD. Conceptualized the overall research, analyzed data, revised and finalized manuscript. 
million blood donations are collected annually around the world [2,3]. Safe blood is blood that is free from any elements that can be harmful to the recipient such as viruses and parasites, etc. [4]. Recruitment of blood donors is significant for the availability of an adequate safe supply of blood and blood products [5]. Safe blood supply requirements and shortages are still critical problems in many developing countries [6].

According to the WHO, an adequate and safe blood supply can be achieved from regular, non-remunerated voluntary blood donors since they tend to avoid risky behavior and maintain healthy status [7]. Young blood donors are the current target population because young people can supply blood regularly for a long-term and they can also advocate and influence other young people to donate blood [6]. In addition to that, the risk of transfusion-transmitted infections (TTIs) tends to be lower in young educated blood donors [8].

The current challenges of Myanmar's blood transfusion service are similar to other developing countries, sustainability of blood supply and getting timely blood supply to all areas of the country [4]. According to the National Blood Center Report for 2018, the voluntary donation rate was $85 \%$ [9]. To reach the WHO goal of $100 \%$ voluntary blood donations by 2020 [10] and to fill the demand, Myanmar needs to actively find strategies to effectively recruit more voluntary blood donors.

In order to donate blood voluntarily, it is important to assess the extent of knowledge regarding blood donation amongst young university and college students. These young students are the best potential sources of donors to provide the safest supply of blood, and by recruiting and retaining them, the country's blood supply can be improved [8]. The knowledge level can be influenced by status such as age, sex, income level, education level and experience of blood donation. Generally, it is assumed that correct knowledge or misinformation acquired from experience and learning can change one's behavior or practice. According to previous studies in Nigeria, Iraq and Ethiopia, knowledge regarding blood donation is significantly associated with the practice of blood donation. In addition, one study reported that despite there being a positive attitude, altruism and willingness to donate blood, misinformation and gaps in knowledge regarding blood donation led to individuals not donating blood. Other reasons for not donating blood such as fear of donating and doubt of selling blood were also reported [11-13].

Yangon being Myanmar's capital city has tertiary level and specialty hospitals and is the main referral center across the country. Therefore, the blood need is more significant than other states and regions. Furthermore, Yangon has the most universities and colleges where blood donation drives are held regularly every year in collaboration with the National Blood Center, Yangon.

Myanmar has no previous studies regarding blood donation amongst young university and college students, who are regarded as the best potential blood donors. More information is required for blood transfusion services to generate strategies and awareness-raising programs focusing on specific gaps of knowledge that the young potential blood donors are lacking. Therefore, this study aimed to (1) determine influencing factors associated with blood donation knowledge, (2) identify knowledge gaps related to blood donation and (3) find reasons for not donating blood in university and college students in Yangon, Myanmar.

\section{Methodology}

Study population and sample size

A cross-sectional survey study (May 2019) was conducted in full-time students of Yangon Technological University (YTU) and National Management Degree College (NMDC) in Yangon, Myanmar which are the institutions with the highest admissions and recruits students from all areas of Yangon. These two nonmedical institutions were purposively selected to avoid selection bias since students from medical-related institutions tend to have 
JHR

36,1

higher knowledge of blood donation. As the university entrance age in Myanmar ranges at around 16-17 years old, 3rd and 4th year (final year) students with an eligible blood donation age of $\geq 18$ years old were included in this study. The total sample size of 320 was calculated by the finite population proportion formula method inclusive of a $10 \%$ missing rate. The sampling method used was a quota and convenience sampling for recruiting participants.

\section{Measurement tool}

Self-administered structured questionnaires were used which covered sociodemographic characteristics, blood donation knowledge with five sub-sections (blood and blood groups, donor eligibility criteria, TTI, blood donation procedures and effect of blood donation on donors) and reasons for not donating blood among nondonor participants. The questionnaires were adapted and modified from the literature review and the National Blood Center, Myanmar [11, 14-20]. The questionnaire's content validity was tested with item-objective congruence (IOC) scoring from three experts and revised according to scores. Reliability of the dichotomous knowledge questionnaire was tested with KR 20 (0.71).

\section{Data analysis}

Data entry and analysis were done by SPSS software version 22.0. Descriptive data were presented by frequency, percentage, mean and standard deviation. Multiple linear regression was performed to identify influencing factors such as age, sex, income level, academic year and previous donation on the blood donation knowledge score. Standardized regression coefficients (B) were used to find significant independent variables in the multiple linear regression model. To find the group difference of a significant independent variable in multiple regression toward total and each sub-section of blood donation knowledge scores, an independent $t$-test was performed. Descriptive analysis was done to compare the incorrect answers between donors and nondonor participants. All analyses were performed at a statistically significant level of $p$-value $<0.05$.

\section{Ethical approval}

The study protocol (No. 063.1/62) received ethical approval from The Research Ethics Review Committee of Research Involving Human Research Participants, Health Sciences Group Chulalongkorn University, Thailand (COA No. 135/2019) in Supplement 1.

\section{Results}

Table 1 shows the sociodemographic characteristics variables of the participants and each group of the variables with a total knowledge score. The average total knowledge score of the participants was $21.18 \pm 3.27$.

Multiple regression analysis to find out influencing factors on the blood donation knowledge showed that only previous donation was statistically significant as shown in Table 2.

The mean scores of sub-sections and total blood donation knowledge scores were compared between blood donors and non-Idonors with the Mann-Whitney $U$ test. Figure 1 shows that all the sub-section scores and total scores were significantly lower in nondonors than blood donors.

Comparison of the incorrect answers among nondonor and donor participants and also total participants is shown in Table 3.

The most incorrectly answered question in the "Blood and blood groups" sub-section was knowledge of universal recipient blood group (Q4, 74.1\%). Nondonors compared to blood 


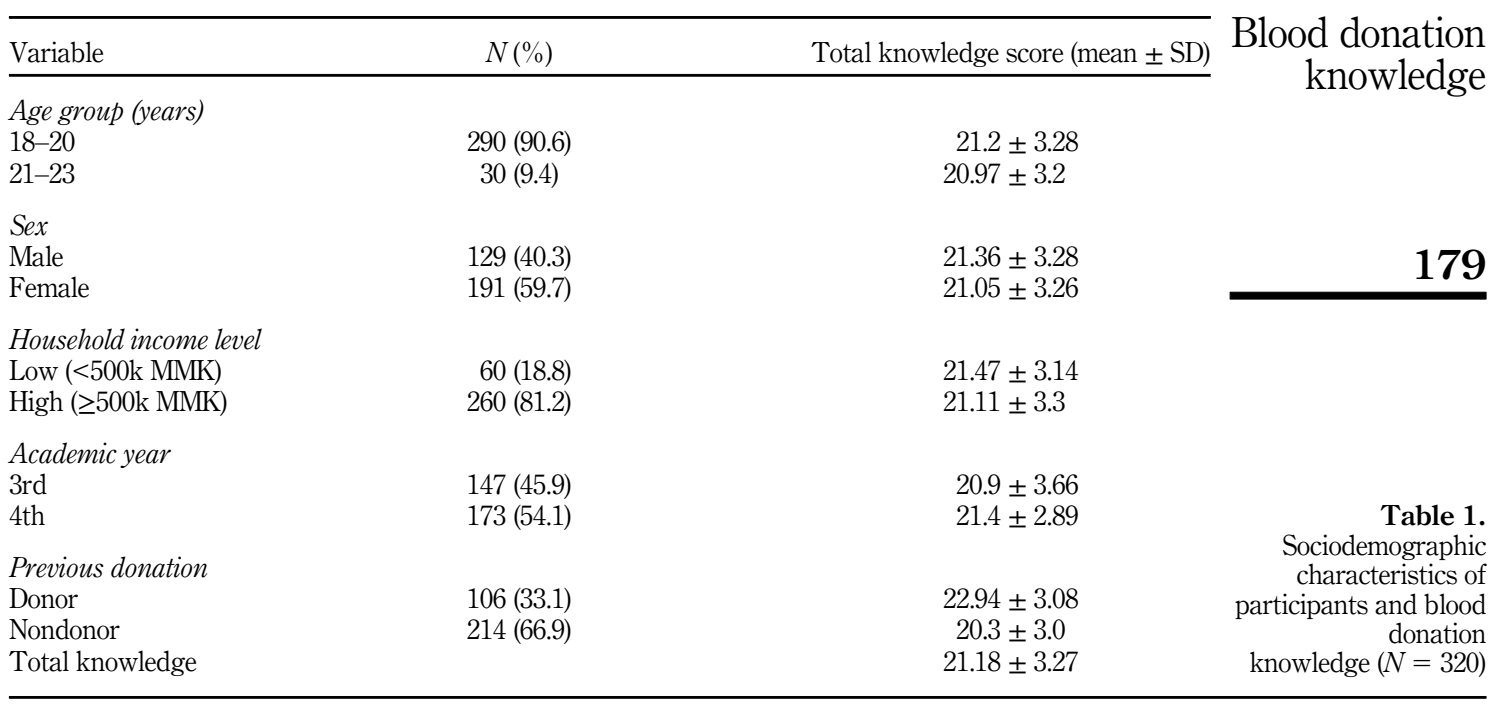

\begin{tabular}{|c|c|c|c|c|c|}
\hline \multirow[b]{2}{*}{ Model } & \multicolumn{2}{|c|}{ Standardized coefficient } & \multirow[b]{2}{*}{$t$} & \multirow[b]{2}{*}{$p$-value } & \multirow{7}{*}{$\begin{array}{r}\text { Table } 2 \\
\text { Sociodemographic } \\
\text { factors and previous } \\
\text { donation on total blood } \\
\text { donation knowledge } \\
\text { score }(N=320)\end{array}$} \\
\hline & $b$ & $\mathrm{SE}$ & & & \\
\hline Age group & -0.030 & 0.610 & -0.548 & 0.584 & \\
\hline Sex & -0.053 & 0.359 & -0.978 & 0.329 & \\
\hline Income level & -0.017 & 0.436 & -0.317 & 0.751 & \\
\hline Academic year & 0.094 & 0.356 & 1.732 & 0.084 & \\
\hline Previous donation & 0.396 & 0.373 & 7.396 & $<0.001^{*}$ & \\
\hline
\end{tabular}

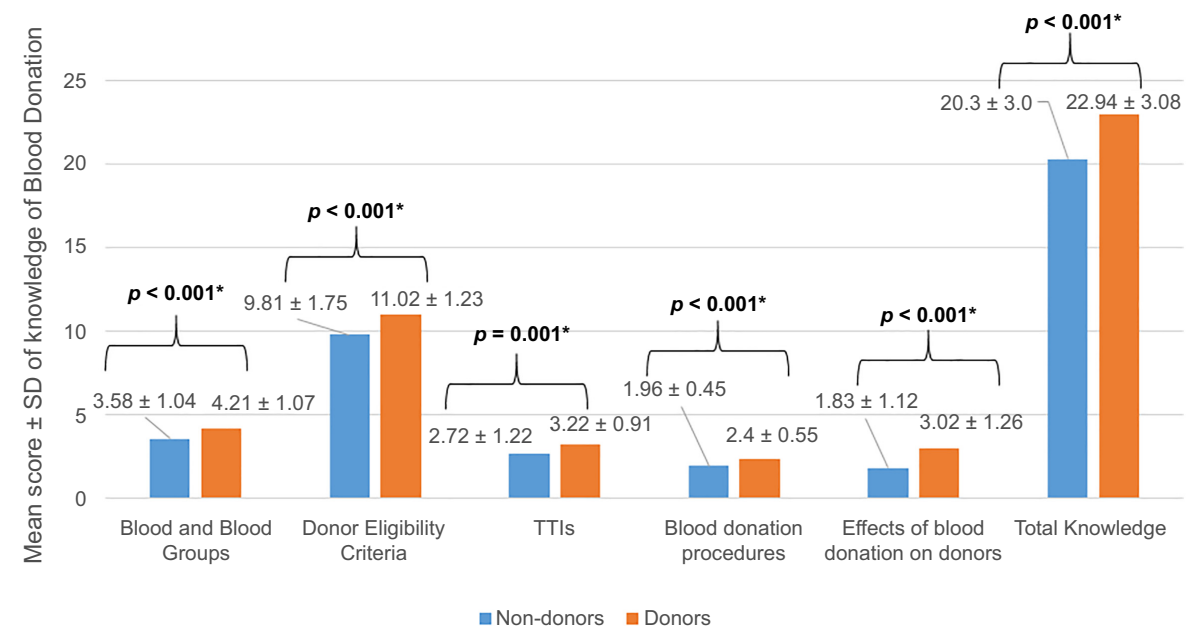

Figure 1.

Comparison of total and sub-section mean scores of blood donation knowledge between blood donors and nondonors by independent $t$-test 
JHR

36,1

Statement

Number $(\%)$

Incorrect answers

Blood and blood groups

1. Average blood volume in human body

180

2. Knowledge of ABO blood group

3. Knowledge of universal donor blood group

4. Knowledge of universal recipient blood group

5. Knowledge of Rh blood group

6. Knowing own blood group

ND

D Total

Donor eligibility criteria

7. Minimum age of blood donation in Myanmar

8. Maximum age of blood donation in Myanmar

9. Minimum body weight to donate blood

10. Minimum interval between two successive blood donations

11. Can donate blood if did not get enough sleep?

12. Can donate blood after alcohol drinking?

13. Can donate blood if not feeling well/have a fever?

14. Can donate blood with tattoo, piercings or acupuncture in last six months?

15. Can donate blood if there is high/low blood pressure?

16. Can donate blood if have anemia?

17. Can donate blood during menstruation?

18. Can donate blood during pregnancy and lactation?

19. It is safe to donate blood for 1st degree relatives

$\begin{array}{ccc}135(63.1) & 47(44.3) & 182(56.9) \\ 72(33.6) & 34(32.1) & 106(33.1) \\ 32(15) & 12(11.3) & 44(13.8) \\ 174(81.3) & 63(59.4) & 237(74.1) \\ 98(45.8) & 33(31.1) & 131(40.9) \\ 7(3.3) & 1(0.9) & 8(2.5)\end{array}$

Transfusion-transmitted Infections(TTIs)

20. HIV can be transmitted from blood

21. Hepatitis can be transmitted from blood

22. Syphilis can be transmitted from blood

23. Malaria can be transmitted from blood

$\begin{array}{ccc}45(21) & 7(6.6) & 52(16.3) \\ 96(44.9) & 35(33) & 131(40.9) \\ 25(11.7) & 5(4.7) & 30(9.4) \\ 133(62.1) & 35(33) & 168(52.5) \\ 30(14) & 16(15.1) & 46(14.4) \\ 14(6.5) & 7(6.6) & 21(6.6) \\ 14(6.5) & 3(2.8) & 17(5.3) \\ 84(39.3) & 23(21.7) & 107(33.4) \\ & & \\ 31(14.5) & 4(3.8) & 35(10.9) \\ 4(1.9) & 1(0.9) & 5(1.6) \\ 65(30.4) & 15(14.2) & 80(25) \\ 40(18.7) & 19(17.9) & 59(18.4) \\ 101(47.2) & 40(37.7) & 141(44.1)\end{array}$

Blood donation procedures

24. Amount of blood removed during blood donation

25 . Donated blood is screened for infection

26. Knowing the meaning of voluntary blood donation

$14(6.5) \quad 1(0.9) \quad 15(4.7)$

$67(31.3) \quad 21(19.8) \quad 88(27.5)$

$82(38.3) \quad 18(17) \quad 100(31.3)$

$110(51.4) \quad 43(40.6) \quad 153(47.8)$

$195(91.1) \quad 55(51.9) \quad 250(78.1)$

$27(12.6) \quad 8(7.5) \quad 35(10.9)$

$1(0.5) \quad 0(0) \quad 2(0.3)$

Table 3.

Comparison of incorrectly answered blood donation knowledge questions between blood donors and nondonors
Effects of blood donation on donors

27. Donor can get infections such as HIV/hepatitis

28. Donor can get anemia or bleeding disorders

29. Donor can gain weight

30. Donor can prevent heart disease and cancer

Note(s): Total $N=320$, Nondonor (ND) $n=214$, Donor $(D) n=106$

$\begin{array}{clr}150(70.1) & 29(27.4) & 179(55.9) \\ 92(43) & 18(17) & 110(34.4) \\ 72(33.6) & 17(16) & 89(27.8) \\ 151(70.6) & 40(37.7) & 191(59.7)\end{array}$

donors answered more incorrect answers notably in the knowledge of ABO blood group (Q1), universal recipient blood group (Q4) and Rh blood groups (Q5).

In the "Donor Eligibility Criteria" sub-section, 52.5\% did not know the minimum interval between two successive blood donations which is four months (Q10). Nondonors also had a much higher percentage of incorrect answers especially in the age range of blood donation $(\mathrm{Q} 7, \mathrm{Q} 8)$, unfit condition of a tattoo, piercing, acupuncture in six months (Q14), blood pressure conditions (Q15) and menstruation (Q17).

In the "Transfusion Transmitted Infections" sub-section, nearly half of all the participants $(47.8 \%)$ did not know that malaria can be transmitted by blood transfusion (Q23), and about half of both nondonors $(51.4 \%)$ and donors $(40.6 \%)$ did not know malaria was a TTI. Nondonors gave more incorrect percentages compared to donors in all the questions (Q20-23). 
In the "Blood donation procedures" sub-section, $78.1 \%$ of the participants did not know the amount of blood removed during blood donation (Q24). Nondonors showed higher incorrect answers percentage in all questions (Q24-26).

In "Effects of Blood Donation on Donors", more than half of the participants did not know the benefit of the blood donation 59.7\%(Q30) and 56\%(Q27) misbelieved that donors can acquire infectious diseases such as HIV/hepatitis. Nondonors had much higher incorrect answers in all the questions than donors (Q27-30).

The top three reasons for not donating blood stated by nondonor participants were "No opportunity to donate" (43\%), "Fear of donating blood" (36\%), and "Still underage to donate blood" $(32.2 \%)$ as in Figure 2. The total percentage exceeded $100 \%$ since it was a multipleresponse question.

\section{Discussion}

With the information of knowledge gaps in donors and nondonors, this study is expected to contribute to suggestions and appropriate interventions for awareness-raising and blood donor recruitment.

Only previous donation history was found to have a significant association with blood donation knowledge. This may reflect the availability of information is somehow limited to blood donors during blood donation and needs to raise awareness amongst all students including nondonors.

Blood donation knowledge of nondonors was significantly lower than that of blood donors in overall knowledge as well as in all the sub-sections. The most incorrect questions of all the participants and knowledge gap between nondonors and blood donors in each sub-section of knowledge questionnaires were discussed as follows.

Blood and blood groups: Knowledge of blood groups such as $\mathrm{ABO}$ and $\mathrm{Rh}$ is important in case of emergency conditions where specific $\mathrm{ABO}$ and $\mathrm{Rh}$ blood groups are needed, for example, $\mathrm{Rh}(-)$ blood groups are relatively rare and can only be transfused by the same $\mathrm{Rh}$ $(-)$ blood group with specific $\mathrm{ABO}$ group.

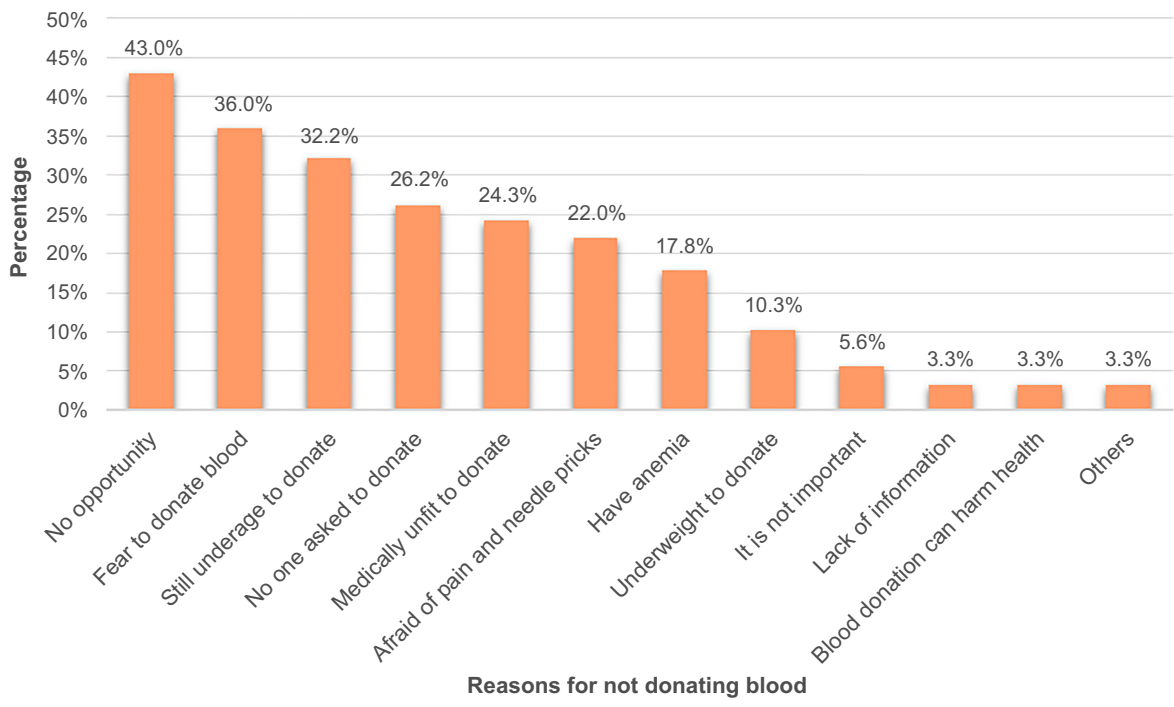

Figure 2. Reasons for not donating blood among nondonor participants 
JHR

36,1

182

Donor eligibility criteria: The information of blood donation intervals and follow-up visits should be clearly informed to all the potential blood donors to maintain the regular blood donation practice in every accessible blood donation site not only in school blood donation campaigns which were generally held once or twice a year. Nondonors had less knowledge of fit and unfit conditions to donate blood and more awareness-raising emphasized the specific topics of incorrect questions as shown in Table 2.

Transfusion-transmitted infections (TTIs): People generally know malaria as a vector transmitted infection and also syphilis as a sexually transmitted infection rather than bloodborne infections. Correct information sharing regarding TTIs is crucial because the residual risk of TTIs is always present even though donated blood is tested with appropriate testing to rule out infection.

Blood donation procedures: It is necessary to inform every potential blood donor to assure only a small amount of blood is collected which cannot harm the health of the donors.

Effect of blood donation on donors: More than half of the participants were not aware that blood donation can prevent health diseases/cancers and also misbelieved that donors can get infections such as HIV/hepatitis. Nondonors also misbelieved that blood donation can cause anemia/blood disorders and weight gain. Such levels of misinformation can lead to negative perceptions of blood donation and can be a barrier to donating blood voluntarily.

The top three reasons for not donating blood from nondonors; (1) "no opportunity", (2) "fear to donate" and (3) "still underage to donate" were supported by other studies [11, 12, 21]. Regular and more frequent blood donation activities in both public and academic settings are needed to create opportunity and experience sharing among the donors and nondonors to overcome the fear. Although recruited participants were already in the eligible blood donation age, many of them thought they were still underage to donate blood. This reflects the knowledge gap of blood donation age in participants.

\section{Conclusion}

The current study showed the existing gaps of blood donation knowledge among university and college students with both blood donor and nondonor aspects. There is significantly lower knowledge in nondonors compared to donors in total as well as in all sub-sections of blood donation knowledge. Blood donation programs should consider giving efficient awareness-raising programs targeting the key population of young adults as well as the population at large. Awareness-raising should reinforce donor eligibility, the interval of blood donations, TTIs and benefits of donating blood to recipients as well as donors, to improve the understanding and thereby motivating the blood donation practice. This can also help in the conversion of one-time donors to repeat regular donors in the future. One of the effective and feasible ways for information sharing is the use of the internet and popular social media platforms among students as well as the general population such as Facebook.

Blood transfusion services should collaborate more with academic and community organizations to hold more frequent blood donation campaigns and also share information of available blood donation sites to create opportunities to donate blood. This study is expected to point out the gaps of blood donation knowledge for the national blood programs to focus on awareness-raising as well as to be able to generate appropriate strategies and interventions for recruiting young blood donors who are key sources of safe and sustainable blood supply.

\section{Limitations}

This study was conducted at two institutions of Yangon and may not be generalized for the student population of the whole country. The sampling method used here is nonprobability quota convenience sampling which might limit the representation of the study population.

Conflict of interest: There is no conflict of interest. 


\section{References}

1. Javadzadeh Shahshahani H, Yavari MT, Attar M, Ahmadiyeh MH. Knowledge, attitude and practice study about blood donation in the urban population of Yazd, Iran. 2004. Transfus Med. 2006; 16(6): 403-9. doi: 10.1111/j.1365-3148.2006.00699.x.

2. World Health Organization [WHO]. Blood safety and availability. [updated 2020; cited 2020 Sept]. Available from: https://www.who.int/news-room/fact-sheets/detail/blood-safety-andavailability.

3. World Health Organization [WHO]. Blood safety and availability. [updated 2017; cited 2020 Sept]. knowledge Available from: http://www.who.int/news-room/fact-sheets/detail/blood-safety-and-availability.

4. Aung T. Status report of the blood transfusion services in Myanmar. Asian J Transfus Sci. 2009; 3(1): 22-5. doi: 10.4103/0973-6247.45258.

5. World Health Organization [WHO]. Voluntary unpaid blood donations must increase rapidly to meet 2020 goal. [updated 2016 Jun 13; cited 2020 Sept]. Available from: http://www.who.int/newsroom/detail/13-06-2016-voluntary-unpaid-blood-donations-must-increase-rapidly-to-meet2020-goal.

6. World Health Organization [WHO]. Towards $100 \%$ voluntary blood donation: a global framework for action. Geneva: WHO; 2010.

7. World Health Organization [WHO]. Universal assess to safe blood transfusion. Geneva: WHO; 2008.

8. World Health Organization [WHO]. World blood donor day 2010: new blood for the world. [cited 2020 Sept]. Available from: http://www.who.int/worldblooddonorday/archives/2010/en/.

9. National Blood Center Myanmar. Status of blood transfusion services 2019. [cited 2020 Sept]. Available from: https://www.donatebloodmyanmar.org/.

10. World Health Organization [WHO]. The Melbourne declaration on $100 \%$ voluntary nonremunerated donation of blood and blood components. [updated 2009; cited 2020 Sept]. Available from: https://www.who.int/worldblooddonorday/MelbourneDeclarationWBDD09.pdf.

11. Ossai EN, Eze NC, Chukwu O, Uguru UA, Ukpai EC, Ihere E. Determinants of practice of blood donation among undergraduate students of Ebonyi State University Abakaliki, Southeast Nigeria. Arch Community Med Public Health. 2018; 4(1): 1-7. doi: 10.17352/2455-5479.000032.

12. Al-Asadi JN, Al-Yassen AQ. Knowledge, attitude and practice of blood donation among university students in Basrah, Iraq: a comparison between medical and non-medical students. Asian J Med Sci. 2018; 9(6): 62-7. doi: 10.3126/ajms.v9i6.20904.

13. Nigatu A, Demissie DB. Knowledge, attitude and practice on voluntary blood donation and associated factors among Ambo University regular students, Ambo Town, Ethiopia. J Community Med Health Educ. 2014; 4: 315. doi: 10.4172/2161-0711.1000315.

14. Abderrahman BH, Saleh MYN. Investigating knowledge and attitudes of blood donors and barriers concerning blood donation in Jordan. Procedia Soc Behav Sci. 2014; 116: 2146-54. doi: 10. 1016/j.sbspro.2014.01.535.

15. Amatya M. Study on knowledge, attitude and practice of blood donation among students of different colleges of Kathmandu, Nepal. Int J Pharm Biol Arch. 2013; 4(3): 424-8.

16. Elias E, Mauka W, Philemon RN, Damian DJ, Mahande MJ, Msuya SE. Knowledge, attitudes, practices, and factors associated with voluntary blood donation among university students in Kilimanjaro, Tanzania. J Blood Transfus. 2016; 2016: 8546803. doi: 10.1155/2016/8546803.

17. Mishra SK, Sachdev S, Marwaha N, Avasthi A. Study of knowledge and attitude among collegegoing students toward voluntary blood donation from north India. J Blood Med. 2016; 7: 19-26. doi: 10.2147/JBM.S91088.

18. National Blood Center Myanmar. Blood donor criteria 2018. [cited XXX]. Available from: https:// www.donatebloodmyanmar.org/. 
JHR

36,1

184

19. Sahoo DP, Patil C, Dehmubed A. A study of knowledge, attitude and practice of voluntary blood donation among interns of a municipal medical college. Int J Community Med Public Health. 2017; 4(4): 1166-70. doi: 10.18203/2394-6040.ijcmph20171343.

20. Pan American Health Organization [PAHO]. Methodological guidelines for socio-cultural studies on issues related to blood donation. Washington, DC: PAHO; 2005.

21. Salaudeen AG, Odeh E. Knowledge and behavior towards voluntary blood donation among students of a tertiary institution in Nigeria. Niger J Clin Pract. 2011; 14(3): 303-7. doi: 10.4103/11193077.86773 .

\section{Corresponding author}

Pramon Viwattanakulvanid can be contacted at:Pramon.V@chula.ac.th

For instructions on how to order reprints of this article, please visit our website: 